\title{
Factors associated with HIV seroconversion in gay men in England at the start of the $21^{\text {st }}$ century
}

\author{
N Macdonald, ${ }^{1,2}$ G Elam, ${ }^{1}$ F Hickson, ${ }^{3} \mathrm{~J}$ Imrie, ${ }^{4} \mathrm{C}$ A McGarrigle, ${ }^{1} \mathrm{~K}$ A Fenton, ${ }^{1,4}$ \\ $\mathrm{K}$ Baster, ${ }^{5} \mathrm{H}$ Ward, ${ }^{1,2} \mathrm{~V}$ L Gilbart, ${ }^{1} \mathrm{R}$ M Power, ${ }^{4}$ B G Evans ${ }^{1}$
}

${ }^{1}$ HIV and STI Department.

Health Protection Agency Centre for Infections, UK; ${ }^{2}$ Department of Infectious Disease Epidemiology, Imperial College Faculty of Medicine, London, UK: ${ }^{3}$ Sigma Research, University of Portsmouth, UK; ${ }^{4}$ Centre for Sexual Health and HIV Research, University College London, London, UK; ${ }^{5}$ Statistics and Modelling and

Bioinformatics Department, Health Protection Agency Centre for Infections, UK

\section{Correspondence to:}

Neil Macdonald, Department of Infectious Disease Epidemiology, Imperial College London, Norfolk Place, London W2 1PG, UK; n.macdonald@imperial.ac.uk

All the authors contributed to the development and writing of the paper. NM, GE, CM, FH, JI, $\mathrm{KF}, \mathrm{VG}, \mathrm{RP}$ and BE contributed to the design and management of the study. In addition, KB and HW contributed to the analysis. All authors have contributed to the drafting, reviewing and revision of the manuscript and have approved the final version.

Accepted 2 November 2007 Published Online First 14 November 2007

\section{ABSTRACT}

Objectives: To detect and quantify current risk factors for HIV seroconversion among gay men seeking repeat tests at sexual health clinics.

Design: Unmatched case control study conducted in London, Brighton and Manchester, UK.

Methods: 75 cases (recent HIV positive test following a negative test within the past 2 years) and 157 controls (recent HIV negative test following a previous negative test within the past 2 years) completed a computerassisted self interview focused on sexual behaviour and lifestyle between HIV tests.

Results: Cases and controls were similar in sociodemographics, years since commencing sex with men, lifetime number of HIV tests, reasons for seeking their previous HIV tests and the interval between last HIV tests (mean $=10.5$ months). Risk factors between tests included unprotected receptive anal intercourse (URAI) with partners not believed to be HIV negative (adjusted odds ratio (AOR) and 95\% confidence interval 4.1, 1.8 to 9.3), where increased risk was associated with concomitant use of nitrite inhalants, receiving ejaculate and increasing numbers of partners. Independent risk was also detected for unprotected insertive anal intercourse (UIAI) with more than one man (AOR 2.7, 1.3 to 5.5) and use of nitrite inhalants (AOR 2.4, 1.1 to 5.2).

Conclusions: HIV serodiscordant unprotected anal intercourse remains the primary context for HIV transmission among gay men, with increased risk associated with being the receptive partner, receiving ejaculate and use of nitrite inhalants. Although the HIV transmission risk of URAI is widely acknowledged, this study highlights the risk of UIAI and that nitrite inhalants may be an important facilitator of transmission when HIV exposure occurs.

Sex between men remains the main focus of HIV transmission in the UK, accounting for over 2300 new diagnoses reported for 2005 and an estimated $84 \%$ of all infections likely to have been acquired within the country. ${ }^{12}$ Surveillance of high risk behaviour and sexually transmitted infections (STIs) among men who have sex with men (MSM) have shown worsening trends in recent years, with the proportion of MSM reporting unprotected anal intercourse in the past year rising to $42 \%$ in 2000 in London and rates of STIs reaching record levels in England and Wales. ${ }^{3}$ The re-emergence of syphilis at the end of the 1990s and lymphogranuloma venereum in 2004 gives further cause for concern for the sexual health of MSM in the UK. ${ }^{5}{ }^{6}$

HIV prevention strategies are based on theories about which behaviours can cause HIV transmission (relative risk) and the prevalence of such behaviours in the population of concern (attributable risk). Risk factor studies were among the earliest responses to the AIDS epidemic. Empirical knowledge of HIV transmission through sex between men has primarily been derived from studies conducted in the first decade of the epidemic. $^{7-11}$ The largest of these was the MultiCenter AIDS Cohort Study, ${ }^{12}$ conducted in epicentres in the USA, which identified unprotected receptive anal intercourse (URAI) as the main risk factor for HIV seroconversion, a finding replicated in most other studies. Behaviours increasing the likelihood of exposure, such as high numbers of sexual partners, and factors thought to increase the probability of transmission, such as the presence of other STIs, have also been reported with varying degrees of consistency. Since there are far more sexual HIV exposures than transmissions, behaviours that facilitate HIV transmission when exposure occurs are important targets for prevention programmes.

Currently, England's HIV prevention strategy for MSM, ${ }^{13}$ first implemented in 1998 and updated in 2003, identifies HIV sero-discordant unprotected anal intercourse, condom failure, the introduction of HIV infected semen into the mouth or anus of uninfected men, concurrent STIs (specifically gonorrhoea, syphilis and herpes) and the absence of post-exposure prophylaxis in men exposed to HIV, as behaviours with sufficient evidence of both relative and attributable risk among MSM in England to warrant being population level targets.

The UK's INSIGHT (Investigation of New Seroconversions In Gay men who HIV Test) Project was established in 2001 to determine whether these factors driving HIV seroconversion in MSM at the beginning of the 21st century remain current, are accompanied by new factors and, if indicated, to inform changes in these population goals/objectives for HIV prevention.

\section{MATERIALS AND METHODS}

A case-control study was conducted at seven sexual health clinics in London (5), Manchester (1) and Brighton (1), which together account for more than half the diagnoses of HIV acquired through sex between men in England. Phased recruitment of participants ran from September 2002 to October 2004, with most clinics recruiting continuously over a 12 month period. Subsets of purposively selected respondents participated in follow up in-depth interviews exploring the context of HIV seroconversion. The results of the qualitative study are reported separately. ${ }^{14} 15$ 


\section{STUDY POPULATION}

Cases (HIV seroconverters) were defined as gay men over 16 years old, who had a recent HIV positive test result at one of the participating clinics, having had an HIV negative test result within the previous two years. Controls were drawn from the same population but had had a HIV negative test result on both occasions. Men whose interval period between tests was less than three months, potentially in the "window period" for antibody detection, were excluded. Cases were given time to adjust to their diagnosis before being recruited but were approached within a month of testing HIV positive. Controls were recruited immediately after receiving their HIV negative test result and any post-test counselling. Clinic staff identified and recruited participants and provided a private space for them to complete the study questionnaire.

\section{STUDY PROCEDURES}

A computer-assisted self interview (CASI) was used to collect data from the participants. The content was guided by current and speculative theories about determinants of HIV transmission, with questions developed from a range of existing studies, and using cognitive interview testing with the initial recruits. The CASI asked about key sexual behaviours (insertive anal intercourse, receptive anal intercourse and receptive oral sex) between their last two HIV tests, in two different ways. First, they were asked to report the aggregate numbers of men, by perceived HIV status (known HIV positive, presumed HIV negative and unknown) at the time the sex occurred. Second, they were asked to report partner specific behaviours with up to three regular partners and aggregate behaviours with casuals. Participants were also asked about use of social and sexual venues and forms of media used to meet sex partners, incident diagnoses of STIs, overall health, clinical depression, and use of alcohol and recreational drugs between their HIV tests. Cases completed the same CASI as controls and submitted their responses via the internet. No questionnaire data were held at the clinic after submission.

All participants provided written informed consent. The study was approved by the South West Multi-centre Research Ethics Committee and local Ethics Committees covering the participating sites.

\section{STATISTICAL ANALYSIS}

Variables were examined to determine their association with HIV seroconversion using Stata (version 9.0; Stata Corp, College Station, TX, USA). Continuous variables were explored using $\mathrm{t}$ tests. For categorical variables odds ratios (OR) $95 \%$ confidence intervals (CI) and $p$ values were obtained using logistic regression. Variables that were associated with being a seroconverter $(p \leqslant 0.2)$ were used as predictor variables in multivariable logistic regression models. This provides a convenient approach to control the associations of interest for any potential confounding factors. Models were constructed using a hierarchical approach based on a proximate-determinants framework similar to Boerma and Weir. ${ }^{16}$ Backward elimination models were used to explore distal factors, retaining those where $p \leqslant 0.2$. For the key sexual behaviour variables, multivariable analysis was restricted to adjusting for any report of URAI with men not believed to be HIV negative.

\section{RESULTS}

\section{Characteristics of HIV seroconverters and controls}

A total of 75 cases and 157 controls were recruited to the study, with an overall response rate of $72 \%$, with no substantial difference in response rates between cases and controls. The two groups were similar in terms of demographics, with a mean age at last HIV test of 35 years, over $90 \%$ white ethnicity, around half educated to degree level and three-quarters were employed (table 1). Seventy-seven per cent of participants described themselves as gay and most were open or completely open to others about their sexuality. Sexual and HIV testing histories were also comparable with cases reporting a mean of 16 years since first anal sex, 7 years since first HIV test, six HIV tests in total and a mean interval of 10.6 months between the last two HIV tests (10.5 for controls).

Cases reported a median of 15 sexual partners in the interval compared to 12 for controls $(p=0.113)$. Forty seven per cent of cases reported sex with at least one man they knew to be HIV positive compared to $36 \%$ of controls, although this difference was not statistically significant. Similarly, there were no significant differences in numbers of sexual partners who were believed HIV negative or of unknown HIV status, the latter comprising the majority of sexual contacts. Anal intercourse was reported by all cases and $97 \%$ of controls.

\section{Factors associated with HIV seroconversion}

Between HIV tests, $83 \%$ of cases and $55 \%$ of controls reported URAI, crude odds ratio (OR) 3.9 (2.0 to 7.7) with increasing risk evident with increasing numbers of men (table 2). URAI with at least one known HIV positive man was reported by $28 \%$ of cases and $11 \%$ of controls (OR 3.2, 1.6 to 6.4). This risk increased sharply where nitrite inhalants were used (OR 9.3, 3.3 to 26.2) and where ejaculation occurred, particularly involving

Table 1 Sociodemographic characteristics, sexual and HIV testing histories of the INSIGHT case-control study participants

\begin{tabular}{|c|c|c|c|c|}
\hline & $\begin{array}{l}\text { Cases } \\
\mathrm{n}=75\end{array}$ & & $\begin{array}{l}\text { Controls } \\
\mathrm{n}=157\end{array}$ & \\
\hline Categorical variables & $\%$ & & $\%$ & \\
\hline \multicolumn{5}{|l|}{ Ethnicity } \\
\hline White & 96 & & 91 & \\
\hline Non-white & 4 & & 9 & \\
\hline \multicolumn{5}{|l|}{ Country of birth } \\
\hline UK & 65 & & 61 & \\
\hline Outside UK & 35 & & 39 & \\
\hline \multicolumn{5}{|l|}{ Education: years since aged 16} \\
\hline Left school with no qualifications & 19 & & 12 & \\
\hline Up to 2 years & 23 & & 17 & \\
\hline More than 3 years & 55 & & 65 & \\
\hline Educated to degree level & 47 & & 54 & \\
\hline \multicolumn{5}{|l|}{ Employment } \\
\hline Employed (full or part time) & 77 & & 77 & \\
\hline Unemployed & 9 & & 8 & \\
\hline Student & 5 & & 8 & \\
\hline \multicolumn{5}{|l|}{ Sexuality } \\
\hline Describes themselves as gay & 77 & & 76 & \\
\hline Completely or open to most about sexuality & 91 & & 85 & \\
\hline Continuous variables & mean & range & mean & range \\
\hline Age at second last HIV test & 34.3 & $18-56$ & 34.2 & $19-66$ \\
\hline Months between last 2 HIV tests & 10.6 & $3-24$ & 10.5 & $3-24$ \\
\hline Age at last HIV test & 35.2 & $20-58$ & 35.1 & $20-66$ \\
\hline \multicolumn{5}{|l|}{ Sexual and HIV testing history } \\
\hline Years since first anal sex & 16 & $1-40$ & 14 & $1-48$ \\
\hline Years since first visit to STI clinic & 10 & $0-38$ & 9 & $0-37$ \\
\hline Years since first ever HIV test & 7 & $0-21$ & 7 & $0-21$ \\
\hline Lifetime number of HIV tests & 6 & $2-20$ & 7 & $2-55$ \\
\hline
\end{tabular}

STI, sexually transmitted infections. 
URAI with more than one HIV positive man (OR 5.5, 1.0 to 28.9). A similar pattern was observed with URAI with men of unknown HIV status (OR 4.3, 2.4 to 7.8), although there was no further increase in risk observed with use of nitrite inhalants in this context, increasing numbers of men, ejaculation and ejaculation with more than one man all showed increased risk. In contrast, no statistical association was found between HIV seroconversion and URAI practises with men believed to be HIV negative (table 2). Significant risks were found for URAI with regular partners (OR 2.4, 1.4 to 4.3) and with casuals (OR 3.7, 2.0 to 6.8 .

Unprotected insertive anal intercourse (UIAI) was reported by $76 \%$ of cases and $61 \%$ of controls (OR 2.1, 1.1 to 3.8), with increased risk for UIAI with more than one man (OR 4.5, 2.5 to 8.0) and to a lesser extent with five or more men (OR 2.5, 1.2 to 4.9). Although men who reported UIAI with known HIV positive and unknown status men were at increased risk of seroconversion, there was no strong evidence for increasing risk with UIAI with increasing numbers of men. Having adjusted for URAI with men not believed to be HIV negative, seroconversion was found to be significantly associated with UIAI with more than one man (adjusted odds ratio (AOR) 2.7, 1.4 to 5.2), more than one man not believed to be HIV negative (AOR 2.0, 1.1 to 3.7) and more than five such men (AOR 2.3, 1.1 to 5.1) (table 2).
Unprotected receptive oral intercourse (UROI) was almost universally reported. Cases were more likely than controls to report UROI with HIV positive men and UROI to ejaculation in their mouth by men of unknown HIV status. However, these behaviours were not found to be statistically significant after adjusting for URAI with men not believed to be HIV negative.

Examination of ancillary sexual behaviours (reported as never, sometimes and often) showed that men who seroconverted were more likely to report any instance of giving oral-anal contact (rimming), group sex, receptive use of sex toys and being fisted (table 3). However there was no evidence of increased risk in men who reported often engaging in these activities (data not shown). A multivariate model of these behaviours suggested that rimming (AOR 3.3, 1.3 to 8.5) and being fisted (AOR 3.1, 1.4 to 7.0) underlay the observed associations (table 3).

Forty-five per cent of cases and 39\% of controls reported a diagnosis of a STI during the interval period (including at the time of their most recent HIV test). Diagnoses of gonorrhoea (OR 3.6, 1.7 to 7.8) and syphilis (6.0, 1.1 to 31.8) were both associated with seroconversion; however, only gonorrhoea remained statistically significant in a multivariate model (table 3).

Table 2 Sexual behaviours of the INSIGHT case-control study participants

\begin{tabular}{|c|c|c|c|c|c|c|}
\hline \multirow[b]{2}{*}{ Any report of: } & \multirow{2}{*}{$\begin{array}{l}\text { Cases } \\
\mathrm{n}=75 \\
\%\end{array}$} & \multirow{2}{*}{$\begin{array}{l}\text { Controls } \\
\mathrm{n}=157 \\
\%\end{array}$} & \multicolumn{2}{|c|}{ Univariable } & \multicolumn{2}{|c|}{ Bivariable* } \\
\hline & & & OR & $95 \% \mathrm{Cl}$ & AOR & $95 \% \mathrm{CI}$ \\
\hline Unprotected receptive anal intercourse & 83 & 55 & 3.93 & $2.00,7.72$ & 0.32 & $0.04,2.59$ \\
\hline with more than 1 man & 60 & 26 & 4.17 & $2.33,7.48$ & 2.05 & $1.02,4.15$ \\
\hline with 5 or more men & 27 & 6 & 5.27 & $2.32,11.97$ & 4.40 & $1.62,11.94$ \\
\hline with HIV positive & 28 & 11 & 3.16 & $1.55,6.44$ & 1.58 & $0.74,3.37$ \\
\hline using nitrite inhalants & 24 & 3 & 9.28 & $3.29,26.19$ & 5.12 & $1.76,14.81$ \\
\hline with more than 1 man & 7 & 3 & 2.70 & $0.70,10.35$ & 1.43 & $0.37,5.58$ \\
\hline with ejaculation & 15 & 3 & 5.16 & $1.72,15.44$ & 2.77 & $0.90,8.50$ \\
\hline with more than 1 man & 7 & 1 & 5.46 & $1.03,28.85$ & 2.95 & $0.55,15.78$ \\
\hline with believed HIV negative & 20 & 23 & 0.86 & $0.43,1.69$ & 0.71 & $0.34,1.46$ \\
\hline using nitrite inhalants & 15 & 10 & 1.57 & $0.68,3.61$ & 1.22 & $0.50,2.94$ \\
\hline with more than 1 man & 5 & 5 & 1.18 & $0.34,4.17$ & 0.69 & $0.18,2.53$ \\
\hline with ejaculation & 12 & 12 & 0.98 & $0.42,2.27$ & 0.78 & $0.32,1.90$ \\
\hline with more than 1 man & 5 & 5 & 1.18 & $0.34,4.17$ & 0.69 & $0.19,2.53$ \\
\hline with not believed HIV negative $\dagger$ & 81 & 44 & 5.57 & $2.88,10.81$ & - & \\
\hline using nitrite inhalants & 51 & 15 & 5.93 & $3.11,11.30$ & 3.21 & $1.54,6.72$ \\
\hline with more than 1 man & 55 & 22 & 4.29 & $2.37,7.76$ & 2.05 & $1.00,4.19$ \\
\hline with 5 or more men & 25 & 5 & 6.23 & $2.58,15.05$ & 3.39 & $1.36,8.47$ \\
\hline with ejaculation & 57 & 21 & 4.97 & $2.73,9.03$ & 2.53 & $1.22,5.24$ \\
\hline with more than 1 man & 35 & 7 & 6.95 & $3.20,15.09$ & 3.85 & $1.69,8.75$ \\
\hline with 5 or more men & 12 & 2 & 6.91 & $1.81,26.34$ & 3.75 & $0.97,14.56$ \\
\hline with regular partners & 59 & 38 & 2.44 & $1.38,4.32$ & 1.12 & $0.60,2.27$ \\
\hline with casuals & 55 & 25 & 3.73 & $2.04,6.81$ & 1.07 & $0.81,3.55$ \\
\hline Unprotected insertive anal intercourse & 76 & 61 & 2.05 & $1.11,3.82$ & 0.32 & $0.39,2.59$ \\
\hline with more than 1 man & 65 & 30 & 4.47 & $2.48,8.03$ & 2.73 & $1.44,5.20$ \\
\hline with 5 or more men & 27 & 13 & 2.45 & $1.23,4.92$ & 1.71 & $0.82,3.57$ \\
\hline with HIV positive & 29 & 14 & 2.49 & $1.27,4.87$ & 1.73 & $0.85,3.53$ \\
\hline with more than 1 man & 8 & 3 & 2.59 & $0.76,8.78$ & 2.18 & $0.59,8.07$ \\
\hline with believed HIV negative & 19 & 25 & 0.68 & $0.34,1.34$ & 0.63 & $0.30,1.31$ \\
\hline with more than 1 man & 7 & 6 & 1.03 & $0.34,3.12$ & 0.68 & $0.21,2.17$ \\
\hline with not believed HIV negative $\dagger$ & 75 & 49 & 3.02 & $1.65,5.56$ & 1.48 & $0.76,2.87$ \\
\hline with more than 1 man & 55 & 27 & 3.22 & $1.81,5.72$ & 1.96 & $1.05,3.68$ \\
\hline with 5 or more men & 25 & 10 & 2.92 & $1.40,6.10$ & 2.34 & $1.07,5.12$ \\
\hline
\end{tabular}

*Controlled for unprotected receptive anal intercourse with men not believed to be HIV negative.

†Combining men of known HIV positive and unknown HIV status. 
Recreational drug use was reported by $93 \%$ of cases and $85 \%$ of controls; however, only $8 \%$ of cases and $3 \%$ of controls reported injecting any drug (mostly steroids). Any use of nitrite inhalants, methylenedioxymethamphetamine (MDMA, Ecstasy), ketamine, d-lysergic acid diethylamide (LSD) and Viagra were all significantly associated with seroconversion (table 3). However, examination of the frequency of drug use (once, more than once and regularly) found no discernable trends in increased drug use with seroconversion (data not shown). A multivariable model of drug use (any) found only nitrite inhalants associated with seroconversion (AOR 3.7, 1.8 to 7.8). Any use of cannabis showed reduced risk (AOR 0.4, 0.2 to 0.9 ), although this "protective" effect was not apparent if regular cannabis use was included in the model. Only 11\% of cases and $12 \%$ of controls reported abstaining from alcohol (table 3).
Ninety-six per cent of cases and 94\% of controls reported meeting new sex contacts during the interval period. However, none of the venues or media reported to meet these men was statistically associated with HIV seroconversion, although a multivariate model indicated that men who used the internet were more likely to seroconvert (AOR 1.9, 1.0 to 3.4) and conversely men who met men in toilets were less likely (AOR 0.3, 0.1 to 0.8 ) (table 3).

A final logistic regression model was used to test the relationship of variables found to be associated with HIV seroconversion thus far: URAI with partners not known to be HIV negative; UIAI with more than one man; a diagnosis of gonorrhoea; rimming another; being fisted; use of the internet to meet men; any use of nitrite inhalants. In the final model, independent associations for HIV seroconversion were found for URAI with partners not known to be HIV negative (AOR 4.1,

Table 3 Association of other factors with HIV seroconversion among the INSIGHT case-control study participants

\begin{tabular}{|c|c|c|c|c|}
\hline & $\begin{array}{l}\text { Cases } \\
n=75\end{array}$ & $\begin{array}{l}\text { Controls } \\
n=157\end{array}$ & Univariable & Multivariable* \\
\hline Any report of: & $\%$ & $\%$ & OR (95\% Cl) & AOR $(95 \% \mathrm{CI})$ \\
\hline \multicolumn{5}{|l|}{ Ancillary sexual behaviours } \\
\hline Insertive oral sex & 96 & 99 & $0.15(0.02,1.50)$ & \\
\hline Being rimmed & 96 & 88 & $3.09(0.88,10.83)$ & \\
\hline Rimming another man & 91 & 78 & $3.09(1.23,7.23)$ & $3.28(1.27,8.46)$ \\
\hline Group sex & 72 & 58 & $1.91(1.04,3.51)$ & \\
\hline Sex toys: receptive & 44 & 28 & $1.95(1.08,3.50)$ & \\
\hline Fisting another man & 32 & 23 & $1.58(0.85,2.95)$ & \\
\hline Being fisted & 25 & 10 & $3.10(1.46,6.60)$ & $3.12(1.40,6.96)$ \\
\hline \multicolumn{5}{|l|}{ Sexually transmitted infections } \\
\hline Gonorrhoea & 27 & 9 & $3.59(1.66,7.77)$ & $4.22(1.82,9.74)$ \\
\hline Non-specific urethritis/Chlamydia & 10 & 19 & $0.51(0.21,1.24)$ & $0.44(0.17,1.13)$ \\
\hline Warts & 9 & 8 & $1.14(0.41,3.18)$ & \\
\hline Syphilis & 7 & 1 & $6.01(1.14,31.80)$ & $4.85(0.86,27.41)$ \\
\hline Pubic lice & 6 & 11 & $0.54(0.17,1.67)$ & $0.39(0.11,1.37)$ \\
\hline Herpes & 4 & 3 & $1.72(0.37,7.92)$ & \\
\hline \multicolumn{5}{|l|}{ Substance use } \\
\hline Alcohol & 89 & 88 & $1.15(0.48,2.77)$ & \\
\hline Nitrite inhalants (poppers) & 80 & 58 & $2.90(1.52,5.55)$ & $3.70(1.75,7.83)$ \\
\hline MDMA (Ecstasy) & 67 & 44 & $2.55(1.44,4.53)$ & $1.71(0.76,3.85)$ \\
\hline Cocaine & 59 & 46 & $1.63(0.94,2.85)$ & \\
\hline Cannabis & 56 & 54 & $1.08(0.62,1.88)$ & $0.43(0.21,0.86)$ \\
\hline Ketamine & 55 & 33 & $2.43(1.39,4.28)$ & $1.99(0.90,4.41)$ \\
\hline Viagra & 53 & 39 & $1.80(1.03,3.14)$ & \\
\hline Speed & 25 & 18 & $1.50(0.78,2.90)$ & \\
\hline GHB (gamma hydroxy butyrate) & 25 & 17 & $1.63(0.84,3.18)$ & \\
\hline Methamphetamine & 16 & 13 & $1.30(0.60,2.83)$ & \\
\hline LSD & 15 & 6 & $2.83(1.12,7.15)$ & $3.19(0.99,10.21)$ \\
\hline Mushrooms & 11 & 8 & $1.44(0.56,3.69)$ & $0.40(0.12,1.34)$ \\
\hline Valium & 11 & 10 & $1.05(0.43,2.58)$ & \\
\hline Steroids & 8 & 4 & $2.19(0.68,7.03)$ & \\
\hline \multicolumn{5}{|l|}{ Venues used to meet men } \\
\hline Bar/club & 66 & 62 & $1.23(0.68,2.18)$ & \\
\hline Internet & 58 & 45 & $1.66(0.95,2.91)$ & $1.85(1.02,3.41)$ \\
\hline Sauna & 53 & 45 & $1.37(0.79,2.39)$ & \\
\hline Cruising ground & 32 & 25 & $1.47(0.80,2.70)$ & $1.77(0.88,3.56)$ \\
\hline Backroom & 32 & 23 & $1.63(0.88,3.02)$ & $1.58(0.80,3.14)$ \\
\hline Private party & 18 & 21 & $0.81(0.40,1.66)$ & \\
\hline Gym & 12 & 18 & $0.65(0.29,1.47)$ & $0.49(0.21,1.17)$ \\
\hline Chat line & 8 & 5 & $1.61(0.54,4.82)$ & \\
\hline Toilet & 7 & 14 & $0.49(0.17,1.27)$ & $0.26(0.08,0.79)$ \\
\hline College/work & 7 & 13 & $0.49(0.17,1.35)$ & \\
\hline
\end{tabular}

*Variables in each tier were entered into a stepwise backwards logistical model retaining those where $p \leqslant 0.2$. 
1.8 to 9.3 ), UIAI with more than one man (AOR 2.7, 1.3 to 5.5 ) and use of nitrite inhalants (AOR 2.4, 1.1 to 5.2).

\section{DISCUSSION}

Although this study did not detect any new factors driving HIV seroconversion among gay men in England, the findings reemphasise the risks associated with unprotected receptive anal intercourse, and clarify the risk associated with nitrite inhalants use during this activity. The risk associated with UIAI has also been clearly identified-a practise that many MSM may mistakenly think low risk.

By recruiting men seeking repeat HIV tests at sexual health clinics we specifically sampled a population at high risk of HIV acquisition. That the sociodemographics, years at risk and HIV testing histories of cases and controls were so similar suggests that potential biases inherent in this methodology have been successfully controlled. In such a sample, where risk profiles of cases and controls closely mirror each other, the factors facilitating transmission (rather than those providing opportunities for exposure) may be expected to be detected. Despite this design, URAI was still found to significantly differentiate seroconverters from non-seroconverters; this finding not only confirms earlier work but adds to likelihood that there have been no major additions to the key behavioural drivers of HIV transmission in this population and that findings from previous studies are still valid.

The study will have underestimated the relative risk of some behaviours owing to the selection of controls who themselves are at increased HIV seroconversion risk since they were having repeated HIV tests. The response rate of over $70 \%$ is unlikely to have introduced bias and although recruitment bias is likely, the indicators presented in table 1 suggest these have been controlled. Using CASI is likely to maximise reporting of sensitive behaviours, but this will not have overcome the recall bias inherent in such studies. Cases were aware of their diagnosis, and controls similarly aware that they were uninfected, and this may have led to differential recall of risk behaviours. The estimated odds ratios of certain unprotected anal and oral sex factors differ markedly between the single and multivariable analysis. It is possible that this is due to some colinearity between these factors. Our ability to detect less prevalent risk factors may be limited by our sample size.

Contrary to findings from the USA, ${ }^{17}$ we found no evidence of methamphetamine's association with seroconversion despite being reported by over $10 \%$ of participants, Rather, the drug that stands out from our study is nitrite inhalants. This independent association has been reported by earlier studies ${ }^{811}$ and from North America more recently. ${ }^{18}{ }^{19}$ That concurrent use of nitrite inhalants during HIV sero-discordant unprotected

\section{Key messages}

- Unprotected anal intercourse with a partner not believed to be HIV negative remains the primary route by which gay men acquire HIV in the UK

- Significant risk are associated with the insertive as well as the receptive mode of intercourse

- Risks from both behaviours increase when engaged with multiple partners

- With the receptive partner, risk is increased by receiving ejaculate and by the concurrent use of nitrite inhalants intercourse facilitates transmission is biologically plausible. ${ }^{20}$ However, an increase in risk may also be because nitrite inhalants are used to facilitate anal penetration and are more likely to be used during "rougher" sex.

Factors found to be associated with seroconversion in multivariate analyses that were later dropped from the final model should not be dismissed. The association of gonorrhoea infection with HIV seroconversion has been reported previously. ${ }^{11}$ One explanation is that men have acquired gonorrhoea from the same partner as they acquired HIV, and gonorrhoea has been shown to increase viral load in semen and in turn the likelihood of onward HIV transmission. ${ }^{21}$ Similarly, that a quarter of cases reported being fisted suggests that engagement in this activity, as well as taking "club" drugs, may be useful markers of men at increased risk of seroconversion. Further research should investigate the role of drugs and alcohol in the context of high risk sexual behaviour.

This study confirms that population level goals or objectives for HIV programmes for gay men should continue to focus on reducing sero-discordant unprotected anal intercourse. While the potential of nitrite inhalants as a transmission facilitator has been acknowledged in England's gay men HIV prevention strategy it has not been adopted as a programmatic target. ${ }^{16}$ This study suggests that this should be considered especially in light of data suggesting that, after alcohol, nitrite inhalants are the most widely used drug among gay men in the UK. ${ }^{22} \mathrm{We}$ therefore conclude that the attributable risk of nitrite inhalants to HIV seroconversion among gay men in the UK is high and that reduction in their use during HIV sero-discordant unprotected intercourse be adopted as a population level goal/ objective by prevention programmes. This recommendation requires further research on the needs associated with avoidance of nitrite use during HIV sero-discordant unprotected anal intercourse, and the interventions that may address these needs.

Acknowledgements: This research was funded by the Medical Research Council (Strategic Grant number G0100183). The authors would like to thank the staff involved in managing the research and recruitment of participants at the sexual health clinics: Camden and Islington Community Health Services NHS Trust, The Royal Free Hampstead NHS Trust, Chelsea and Westminster Healthcare and NHS Trust, Kings Healthcare NHS Trust, St Mary's NHS Trust, Brighton NHS Trust, Central Manchester Healthcare NHS Trust; André Charlett for statistical advice; Professor Jonathan Elford for contribution to the INSIGHT questionnaire; all the men who participated.

Funding: The work for this paper was funded by a Strategic Grant from the Medical Research Council Sexual Health and HIV Research Strategy Committee.

Competing interests: None.

\section{REFERENCES}

1. Health Protection Agency Centre for Infections and Health Protection Agency Scotland. Unpublished Quarterly Surveillance Tables No 71, 06/2 Table 5: http://www.hpa.org.uk/infections/topics az/hiv and sti/hiv/epidemiology/files/ 200602(Jun)_New_HIV_Quarterlies.pdf (accessed 25 July 2007).

2. The UK Collaborative Group for HIV and STI Surveillance. Focus on Prevention HIV and other Sexually Transmitted Infections in the United Kingdom: 2004.London Health Protection Agency Centre for Infections November 2004: http:// www.hpa.org.uk/infections/topics az/hiv and sti/publications/annual2004/ fop_5_populationsubgroups.pdf (accessē 25 July 2007).

3. Dodds JP, Mercey DE, Parry JV, et al. Increasing risk behaviour and high levels of undiagnosed HIV infection in a community sample of homosexual men. Sex Transm Infect 2004;80:236-40.

4. Macdonald N, Dougan S, McGarrigle C, et al. Recent trends in diagnoses of HIV and other sexually transmitted infections in England and Wales among men who have sex with men. Sex Transm Infect 2004;80:492-7.

5. Simms I, Fenton KA, Ashton M, et al. The re-emergence of syphilis in the United Kingdom: the new epidemic phases. Sex Transm Dis.2005;32(4):220-6.

6. Macdonald N, Ison C, Martin I, et al. Initial results of enhanced surveillance for lymphogranuloma venereum (LGV) in England. Euro Surveill 2005;10(1):E050127.5.

7. Marmor M, Friedman-Kien AE, Laubenstein L, et al. Risk factors for Kaposi's sarcoma in homosexual men. Lancet 1982;1:1083-7. 
8. Melbye M, Biggar RJ, Ebbesen P, et al. Seroepidemiology of HTLV-III antibody in Danish homosexual men: prevalence, transmission, and disease outcome. $\mathrm{Br}$ Med J (Clin Res Ed) 1984;289:573-5.

9. Jeffries $\mathbf{E}$, Willoughby B, Boyko WJ, et al. The Vancouver Lymphadenopathy-AIDS Study: 2. Seroepidemiology of HTLV-III antibody. Can Med Assoc J 1985;132(12):1373-7.

10. Winkelstein W, Lyman DM, Padian N, et al. Sexual practices and risk of infection by the human immunodeficiency virus. The San Francisco Men's Health Study. JAMA 1987;257(3):321-5

11. Moss AR, Osmond D, Bacchetti $P$, et al. Risk factors for AIDS and HIV seropositivity in homosexual men. Am J Epidemiol 1987:25:1035-47.

12. Kingsley LA, Detels R, Kaslow R, et al. Risk factors for seroconversion to human immunodeficiency virus among male homosexuals. Results from the Multicenter AIDS Cohort Study. Lancet 1987;14:345-9.

13. Hickson F, Nutland W, Weatherburn P, et al. Making It Count: A collaborative planning framework to reduce the incidence of HIV infection during sex between men. London; Sigma Research, 2003.http://www.sigmaresearch.org.uk/downloads/ report03e.pdf (accessed 25 July 2007).

14. Elam G, Macdonald N, Fenton K, et al. Intentional and unintentional UAl among gay men who HIV test in the UK: qualitative results from an investigation into risk factors for seroconversion among gay men who HIV test (INSIGHT). HIV Med 7 (supplement 1), abstract 027,2006

15. Elam G, Macdonald N, Fenton K, et al. The role of HIV testing in risk perceptions and safer sex strategies: qualitative results from an investigation into risk factors for seroconversion among gay men who HIV test. HIV Med 7 (supplement 1), abstract P83, 2006.

16. Boerma JT, Weir SS. Integrating demographic and epidemiological approaches to research on HIV/AIDS: the proximate-determinants framework. J Infect Dis 2005;1(191 Suppl 1):S61-7

17. Urbina A, Jones K. Crystal methamphetamine, its analogues, and HIV infection: medical and psychiatric aspects of a new epidemic. Clin Infect Dis 2004;38:890-4.

18. Buchbinder SP, Vittinghoff E, Heagerty PJ, et al. Sexual risk, nitrite inhalant use, and lack of circumcision associated with HIV seroconversion in men who have sex with men in the United States. J Acquir Immune Defic Syndr 2005;39:82-9.

19. Lampinem TM, Matthesis K, Chan K, et al. Nitrite inhalant use among young gay and bisexual men in Vancouver during a period of increasing HIV incidence. BMC Public Health 2007; 7:35

20. Seage GR 3rd, Mayer $\mathrm{KH}$, Horsburgh $\mathrm{CR} J \mathrm{~J}$, et al. The relation between nitrite inhalants, unprotected receptive anal intercourse, and the risk of human immunodeficiency virus infection. Am J Epidemiol 1992;135:1-11.

21. Rottingen JA, Cameron DW, Garnett GP. A systematic review of the epidemiologic interactions between classic sexually transmitted diseases and HIV: how much really is known? Sex Transm Dis 2001;28:579-97.

22. Weatherburn $\mathbf{P}$, Stephens $\mathbf{M}$, Reid D, et al. Vital Statistics: Findings from the Gay Men's Sex Survey 1999, Sigma Research: London: 14, 2000. http:// www.sigmaresearch.org.uk/downloads/report00b.pdf (accessed 25 July2007).

\section{FUNDING AVAILABLE FOR RESEARCH PROJECTS}

The Committee on Publication Ethics (COPE) has established a Grant Scheme to fund research in the field of publication ethics. The Scheme is designed to provide financial support to any member of COPE for a defined research project that is in the broad area of the organisation's interests, and specifically in the area of ethical standards and practice in biomedical publishing. The project should have a specific goal and be intended to form the kernel of a future publication.

A maximum sum of $£ 5000$ will be allocated to any one project, but applications for smaller sums are welcomed.

The terms and conditions of the Grant are as follows:

- At least one of the applicants must be a member of COPE.

- Calls for applications will be made twice a year with closing dates of 1 December and 1 June. An electronic version of the application form must be sent to the Administrator no later than $12 \mathrm{pm}$ (noon GMT) on the closing date for consideration by COPE Council.

- The application must contain a lay summary of the project, a definition of the question to be posed, sufficient methodological detail to allow assessment of the viability of the project, a clear timeline and a definition of the likely deliverables. A full justification for the sum requested must accompany the application.

- A report on the progress of the research should be presented within one year of the award and at the end of the project. The grant must be used within two years from the date of award, and balance sheets must be forwarded annually. These should be sent to the Administrator. Any remaining funds after two years must be returned.

- It is anticipated that the work stemming from the project will be presented at one of COPE's annual seminar meetings within 2-3 years of the award. Such data may also be published in peer-reviewed journals. Any publications or related presentations at meetings by the recipient emanating in part or whole from COPE's support should be duly acknowledged and copies sent to the Administrator.

Applications are reviewed by a COPE sub-committee. Applicants will be advised of a decision as soon as practicable after the deadline date.

An application form can be obtained by contacting Linda Gough, COPE administrator, at LGough@ bmj.com or 0207383 6602. For more information on COPE, see http://www.publicationethics.org.uk/

The closing date for receipt of applications is 1 December 2007 or 1 June 2008. 